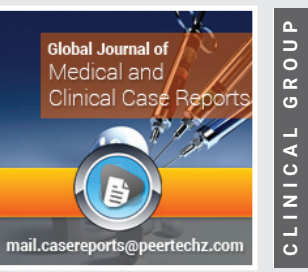

\section{Lessons learned from study of WWII Veterans with Dementia}

\author{
Hanna Ulatowska* \\ Professor, School of Behavioral and Brain Sciences, The University of Texas at Dallas, 1966 Inwood \\ Road Mail Station CD Dallas, Texas 75235, United States
}

Received: 07 August, 2020

Accepted: 13 August, 2020

Published: 14 August, 2020

*Corresponding author: Dr. Hanna Ulatowska, Professor, School of Behavioral and Brain Sciences, The University of Texas at Dallas, 1966 Inwood Road Mail Station CD Dallas, Texas 75235, United States, Tel: (214)-357-1975; Fax: 214-905-3006;

E-mail: hanna@utdallas.edu

ORCID: https://orcid.org/0000-0002-4585-9658

https://www.peertechz.com

Check for updates

\section{Introduction}

In our six-year study, Dr. Ulatowska and her coworkers collected the testimonial language of eighty WWII veterans who volunteered to participate in semi-structured interviews about their wartime experiences. The veterans of WWII have a unique shared group of identities and values that are characteristic of this period in American culture which is well documented in the literature [1]. These identities and values were strengthened over time as the veterans began going through the process of life review during middle age. Through the process of life review, a person reflects on their past and present life experiences and values and integrates them to strengthen their personal identity [2]. The beginning of the life review process coincided with American's increased desire to learn about WWII and hear the stories of the veterans which encouraged veterans to not only reflect on their experiences but to share them through having conversations, giving school presentation, and writing autobiographies. Of the eighty veterans who participated in the study, eight had either mild or moderate dementia. One of the questions we explored is whether WWII veterans with dementia were still capable of expressing their identity via narratives. This study shows that WWII veterans with mild dementia do have the same identities as healthy WWII veterans but express these identities with simple language and require the assistance of communicative strategies and encouragement from the interviewer and/ or family. Despite cognitive impairment, persons with mild dementia demonstrate preserved abilities which enable them to meaningfully interact with their environment $[3,4]$. Opportunities for narrative discourse is a basic communication need rarely provided to individuals with dementia and persons with dementia often report a lack of acknowledgment and loss of personhood $[2,5,6]$. This results in the isolation from one's environment and limited communication with others which is detrimental to the continued quality of life of these individuals $[7,8]$. Our research observations and findings therefore have important clinical value for those working with people with dementia.

\section{Materials and methods}

WWII veterans responded to notices at veterans' associations, assisted and independent living centers, day centers for people with dementia, and local aviation museums. A total of 77 male and 3 female veterans participated in the study overall, of which 8 were diagnosed with dementia. These 8 veterans were previously diagnosed with dementia and disclosed this information before participating in the study; their cognition status was measured using the mini mental state examination (MMSE). The veterans with dementia had a mean age of 88.2 years (range $=86-91$ years), with a mean education of 13.8 years (range $=11-16$ years). Family members (spouses or adult children) were sometimes present to support the veterans or elaborate on stories told by the veteran.

Semi-structured interviews were audio-recorded for later transcription and analysis and were primarily taken in the home during one meeting. The semi-structured interview format was successful in eliciting the identities of veterans because its minimal structure enabled veterans to share the stories they considered most personally meaningful. The interviewer modified her communicative style to encourage the veterans with dementia to respond and adapted the phrasing of questions as needed to increase understanding. Closedended questions such as "What branch were you in: the Army, the Navy, or the Marine Corps?" supported the veterans with dementia. However, many of the responses elicited were spontaneously produced comments; the interviewer allowed the veteran to dictate the length and level of detail of their response to prompts such as "How did you first decide to go 
into the military?" and encouraged them to continue with the use of the interjection "mm-hmm" to indicate interest and encourage the veteran to continue.

\section{Results}

The semi-structured interview format allowed for a more relaxed, naturalistic exchange between interviewer and veteran and allowed for expressions of identity such as humor. Several of the veterans with dementia felt comfortable joking during the interview, some even telling self-depreciating jokes. This indicates that despite their memory impairment, veterans with dementia had the strong narrative identity necessary to communicate effectively and connect with their interviewer through humor.

The semi-structured interview format also elicited another expression of narrative identity, metaphoric statements. One of the most unexpected findings of our study was that veterans with dementia could produce wisdom and identity via metaphoric language, despite their language and memory impairments. One veteran produced a metaphor reflecting the value of perseverance present in this generation of Americans. He conveyed through his metaphor that ultimate success is not always a necessary goal, and just completing a task is often more meaningful and important.

The high accessibility of memories in dementia is strongly related to certain memories and one's identity, whereby individuals with dementia tend to select autobiographical memories which are self-defining. The veterans with dementia had particularly strong identities as patriots and as survivors. They identified strongly as Americans and as veterans and felt they fought in a good war. They also felt grateful for their survival and several felt they had a duty to externalize their gratitude for survival through making a positive impact on the world. Pilots also strongly identified with that label and placed high importance on the length of wartime experience, their rank, and the records set, or awards received. Pilots, both in general and in the dementia group specifically, had both the highest educational level on average and the strongest identities compared to other servicemen. This allowed pilots with dementia to manage their communicative and cognitive difficulties more effectively.

The veterans with mild dementia were all aware of their communicative difficulties and compensated through using communicative strategies to ensure their message was understood. The most common of these was repetition. The veterans with dementia used repetition both for emphasis and when they sensed their listener had not understood them. The veterans with dementia were willing to participate in our study, despite any frustration or embarrassment they might feel because of their communicative difficulties. This demonstrated their strong identity and morals and their commitment to fulfill their duty as patriots.

The presence and expression of these identities in the veterans with dementia indicates that they have already undergone the process of life review, because these identities are made up of information gained through life review. The process of life review begins in middle age before the onset of dementia, so they were able to retain their identity in the early stages of dementia. As a result, the veterans were able to produce the information that was most important to them. However, due to their deficits in memory and cognition, their specificity in recounting their wartime experiences was reduced.

\section{Discussion}

The clinical implications of this study are manifold. Personcentered dementia care must emphasize what is preserved as opposed to what is lost $[2,5]$. Maintaining identity for a longer period is crucial to dementia care because it focuses on the identity the individual still has and personalizes their care. Sharing narratives affirms personhood in dementia and promotes respect and acceptance for these individuals. Sharing personal stories values the person's lived experiences and an understanding of his/her reality $[6,9]$. Understanding the identity of persons with dementia - such as their roles, preferences, values, interests - may be utilized in developing programs and activities which would address their social and emotional needs and increase their quality of life. The semistructured interview format is an ideal format for eliciting expressions of identity from people with dementia because it can be modified to best support the individual and can be conducted in a naturalistic way. Personal memories - particularly highly emotional ones - remain strongly throughout life, even in dementia [6]. Therefore, caregivers can enhance the personal and social identity of those with dementia by providing them a means to express their identities and acknowledging their individuality.

\section{References}

1. Hanna U, Olea Santos T, Garst Walsh D, Aguilar S, Patterson R, et al. (1997) In Press. Trauma and Reconciliation in Testimonial Language of World War II Veterans. Journal of Aging and Social Change

2. Hanna U, Olea Santos T, Garst Walsh D (2018) From Stories to Wisdom: Communicative Competence in Testimonial Language of World War II Pilot Veterans. Journal of Aging and Social Change 8: 17-26. Link: https://bit.ly/3fPw2tr

3. Molly A (2010) Beyond Narrative: The Shape of Traumatic Testimony. In We Shall Bear Witness: Life Narratives and Human Rights, edited by Matt Hyvärinen, Lars-Christer Hydén, Marja Saarenheimo, and Maria Tamboukou Madison: University of Wisconsin Press 147-166. Link: https://bit.ly/30Rom5J

4. Clive B (2006) The Narrative Dispossession of People Living with Dementia: Thinking About the Theory and Method of Narrative. In Narrative, Memory and Knowledge: Representations, Aesthetics and Contexts, edited by Kate Milnes, Christine Horrocks, Nancy Kelly, Brian Roberts, and David Robinson, Huddersfield: University of Huddersfield Press 101-109. Link: https://bit.ly/30PneQ8

5. Clive B (2008) Towards a Person-Centered Ethic in Dementia Care: Doing Right or Being Good. In Excellence in Dementia Care: Principles and Practices, edited by Murna Downs and Barbara Bowers. Berkshire: Open University Press 103-118.

6. Marie MA (1997) Narrative Identity and Dementia: A Study of Emotion and Narrative in Older People with Dementia. Ageing and Society 17: 673-698. Link: https://bit.ly/31PzSh5 
7. Andrea C, Clegg D (2013) Behind the Stiff Upper Lip: War Narratives of Older Men with Dementia. Journal of War \& Culture Studies 6: 239-254. Link: https://bit.ly/3amrEkC

8. Arthur F (1997) The Wounded Storyteller: Body, Illness, and Ethics. Chicago: University of Chicago Press. Link: https://bit.ly/33VG7Ti
9. Tom K, Bredin K (1992) Towards a Theory of Dementia Care: Personhood and Well-Being. Ageing \& Society 12: 269-287. Link: https://bit.ly/2DQI61H
Discover a bigger Impact and Visibility of your article publication with

\section{Peertechz Publications}

\section{Highlights}

* Signatory publisher of ORCID

* Signatory Publisher of DORA (San Francisco Declaration on Research Assessment)

* Articles archived in worlds' renowned service providers such as Portico, CNKI, AGRIS, TDNet, Base (Bielefeld University Library), CrossRef, Scilit, J-Gate etc.

* Journals indexed in ICMJE, SHERPA/ROMEO, Google Scholar etc.

- OAI-PMH (Open Archives Initiative Protocol for Metadata Harvesting)

* Dedicated Editorial Board for every journal

* Accurate and rapid peer-review process

* Increased citations of published articles through promotions

* Reduced timeline for article publication

Submit your articles and experience a new surge in publication services

(https://www.peertechz.com/submission).

Peertechz journals wishes everlasting success in your every endeavours.

Copyright: () 2020 Ulatowska $\mathrm{H}$. This is an open-access article distributed under the terms of the Creative Commons Attribution License, which permits unrestricted use distribution, and reproduction in any medium, provided the original author and source are credited.

Citation: Ulatowska H (2020) Lessons learned from study of WWII Veterans with Dementia. Glob J Medical Clin Case Rep 7(2): 067-069. 